\title{
Diseño y Construcción de un filtro de agua vegana.
}

\section{Design and construction of a vegan water filter.}

Diego Fernando Mayorga Pérez. ${ }^{1}$, Isidoro Enrique Tapia Segarra. ${ }^{2}$, Ligia Elizabeth Paredes. ${ }^{3}$ \& Jorge Isaias Caicedo Reyes. ${ }^{4}$

\begin{abstract}
.
DOI: https://doi.org/10.33262/cienciadigital.v3i3.649

The objective of the present project is to develop a filter in order to obtain water of sufficiently good quality for the people or the vegan community. Vegan people have a strict lifestyle in terms of their health, and consumption of articles of animal origin, and according to the point of view of the vegan community dictates that drinking water is not good enough for consumption, because to the chemical substances to which they are subjected in order to be potable, so for them, drinking water should be obtained from natural springs, and if this is not in good condition, it should be filtered with a natural procedure, such as the water cycle on Earth. A filter has been made with sand, gravel, activated carbon and cotton, based on bibliographic sources and with elements found in nature without any industrial procedure. Samples were taken of two waters, one contaminated and another cleaner, to evaluate the effectiveness of the filter, this yielded good results in both slope A where it could clarify the color and reduce a little the other pollutants, going into the parameters to make it consumable, but still not enough for the vegan community, while for the B side, its source is cleaner, and for this case, the water turned out to be contaminated instead of being filtered, finally concluding that the filter is not suitable for the initial purpose.
\end{abstract}

Keywords: Vegan, Shed, Gravel, Activated Carbon.

\footnotetext{
${ }^{1}$ Escuela Superior Politécnica de Chimborazo, Chimborazo, Ecuador, diego.mayorga @espoch.edu.ec

${ }^{2}$ Escuela Superior Politécnica de Chimborazo, Chimborazo, Ecuador, itapia@espoch.edu.ec

${ }^{3}$ Escuela Superior Politécnica de Chimborazo, Chimborazo, Ecuador, ligia.paredes@espoch.edu.ec

${ }^{4}$ Escuela Superior Politécnica de Chimborazo, Chimborazo, Ecuador, isaias.caicedo@espoch.edu.ec
} 


\section{Resumen.}

El proyecto presente tiene como objetivo elaborar un filtro con el fin de poder obtener agua con la calidad suficientemente buena para la gente o comunidad vegana. Las personas veganas tienen un estilo de vida estricta en cuento se refiere a su salud, y consumo de artículos de procedencia animal, y según el punto de vista de la comunidad vegana dicta que el agua potable no es lo suficientemente buena para su consumo, debido a las sustancias químicas a las que se someten para poder ser potable, es así que para ellos, el agua de consumo debería ser obtenido de vertientes naturales, y si esta no está en buenas condiciones, se lo debería filtrar con un procedimiento natural, como el ciclo del agua en la Tierra. Se ha elaborado un filtro con arena, gravas, carbón activado y algodón, basándose en fuentes bibliográficas y con elementos encontrados en la naturaleza sin ningún procedimiento industrial. Se tomó muestras de aguas de dos vertientes, una contaminada y otra más limpia, para evaluar la efectividad del filtro, esto arrojó resultados buenos en tanto a la vertiente A en donde se pudo aclarar el color y reducir un poco los demás contaminantes, adentrándose a los parámetros para hacerlo consumible, pero aun así no lo suficiente para la comunidad vegana, mientras que para la vertiente B, su fuente es más limpia, y para este caso, el agua resulto ser contaminada en vez de ser filtrada, concluyendo finalmente que el filtro no es adecuado para el propósito inicial.

Palabras claves: Vegana, Vertiente, Grava, Carbón Activado.

\section{Introducción.}

El agua es la fuente de toda la vida en la Tierra. Su distribución es muy variable: en algunas regiones es muy abundante, mientras que en otras escasea. Sin embargo, contrario a lo que muchas personas creen, la cantidad total de agua en el planeta no cambia.

El agua existe en forma sólida (hielo), líquida y gaseosa (vapor de agua) estados que podemos observar en océanos, ríos, nubes, lluvia y otras formas. Así, el agua superficial se evapora, el agua de las nubes precipita, la lluvia filtra en el suelo y corre hacia el mar. Al conjunto de procesos involucrados en la circulación y conservación del agua en el planeta se le llama ciclo hidrológico o, de manera más precisa, ciclo geo- hidrológico.

La calidad del agua de las urbanizaciones y regiones rurales es apta para el consumo humano ya que mediante procesos químicos y físicos se alcanzan los parámetros admisibles para el consumo humano, a pesar de los procesos de potabilización para la comunidad vegana el agua potable no es consumible ya que presenta varios químicos que inciden en su composición; es por eso que según su ideología ellos ven mucho más factible tratar directamente y de manera natural el agua proveniente de vertientes para su posterior consumo ya que la consideran mucho más pura y amigable con el medio ambiente. 
Es por eso que hoy en día surge la necesidad de contar con dispositivos ecológicamente amigables, prácticos y que permitan un eficiente proceso de purificación, además debe ser accesible para gran parte de la comunidad vegana y en general, en vista de esto se pretende elaborar un filtro purificador de agua cuya estructura sea sencilla y que a la vez cumpla con la con sus propósitos de purificación.

\section{Marco Teórico}

\section{A. Disposición del agua en la Tierra.}

El $97.5 \%$ del agua en la Tierra se encuentra en los océanos y mares de agua salada, únicamente el restante $2.5 \%$ es agua dulce. Del total de agua dulce en el mundo, 69\% se encuentra en los polos y en las cumbres de las montañas más altas y se encuentra en un estado sólido.

El 30\% del agua dulce del mundial, se encuentra en la humedad del suelo y en los acuíferos profundos. Solo el 1\% del agua dulce en el mundo, escurre por las cuencas hidrográficas en forma de arroyos y ríos y se depositan en lagos, lagunas y en otros cuerpos superficiales de agua y en acuíferos [1].

Sólo el $0.007 \%$ del agua existente en la Tierra es potable, y esa cantidad se reduce año tras año debido a la contaminación [2].

\section{B. Calidad de Agua en Riobamba}

Según los estudios realizados por la Universidad Nacional de Chimborazo (UNACH), Indica que en gran parte del cantón Riobamba el agua consumida cumple con los estándares establecidos en la norma NTE-INEN 1108 QUINTA REVISIÓN 2014-01. Dicha norma tiene como alcance establecer los requisitos que debe cumplir el agua potable para consumo humano, esta se aplica para los sistemas de abastecimiento públicos y privados a través de redes de distribución y tanqueros [3]. En la Fig. 1., se muestra el porcentaje del total de las parroquias que llegan a cumplir con la norma anteriormente especificada.

Fig. 1. Distribución porcentual de la calidad del agua del cantón Riobamba [4].

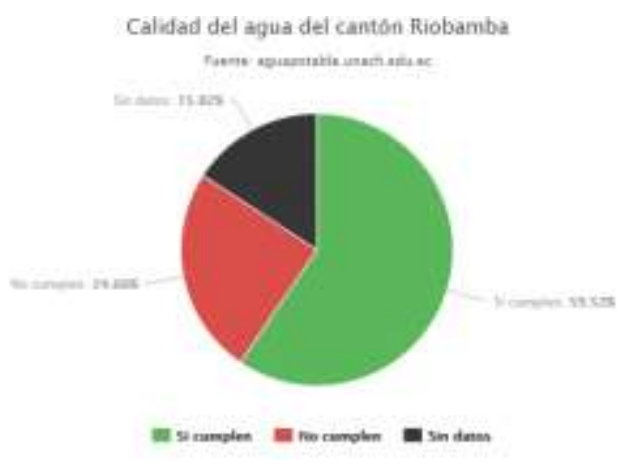


Uno de los barrios que cumple con la norma, es los Álamos ubicado en la Parroquia Lizarzaburu, cuya composición química se muestra en la Fig. 2.

Fig. 2. Composición química del agua en el sector Lizarzaburu/Alamos/Alamos.

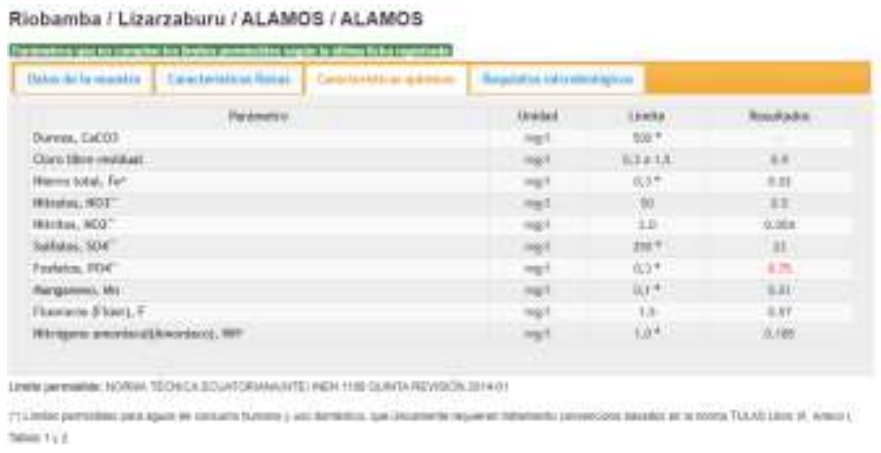

Los resultados mostrados evidencian que en el proceso de potabilización se agregan varios compuestos químicos como: fosfatos, nitritos, amoniaco, cloro y sulfatos para purificar agua, es por eso por lo que la comunidad Vegana no la considera apta para su consumo.

\section{Vegano.}

Es aquella persona que sigue un régimen alimenticio basado en el consumo de frutas, verduras y legumbres, al tiempo que se caracteriza por la abstención del consumo de carne y pescado y, en ocasiones, de otros alimentos o aditivos de origen animal como el huevo, la leche, la miel.

En estos días los veganos han llegado a tener un estilo de vida más estricto, con el pasar del tiempo, llegando a evitar cualquier producto derivado de animales y de elementos naturales, sean estos en ropa, zapatos, accesorios, entre otros. Hoy en día ellos buscan que tanto la manufactura, tratamiento y distribución sea amigable con el medio ambiente.

\section{Materiales de un filtro vegano.}

\section{1) Arena}

Este material permite retener las partículas contaminantes presentes en el agua, cuyo tamaño no supere las $20 \mu$, la arena forma una capa biológica que desarrolla procesos de degradación biológica y química para reducir a los contaminantes retenidos.

\section{2) Carbón activado}

Este material juega un papel importante en el proceso de filtrado ya que permite eliminar tanto compuestos orgánicos como el cloro presente en el agua, este se lo emplea de forma granular y puede ser proveniente de cascaras de coco, coque de petróleo, serrín o turba. El 
carbón sometido a elevadas temperaturas modifica su estructura volviéndose más poroso permitiendo así absorber de mejor manera químicos tóxicos presentes en el agua [5].

\section{3) Grava.}

Esta puede ser de diferente tamaño (grande, pequeña o mediana) y tiene como objetivo retener las partículas de tamaño considerable como piedras, residuos de madera, plásticos, etc. Se considera como el primer material presente en un filtro ya que a partir de aquí el agua descenderá libremente hacia los otros materiales de filtrado [6].

\section{4) Algodón}

Consiste en la última etapa de filtrado ya que el agua proveniente hasta este punto en su mayor parte está totalmente sin partículas contaminantes, en donde dependiendo del grado de suciedad permanente aun el algodón obstruye rápidamente y reduce la circulación del agua en el filtro. Las capas de algodón de un filtro deben ser cambiadas constantemente para evitar la acumulación de suciedad y por ende la proliferación de bacterias [7].

Fig. 3. Esquema del filtro dispuesto desde la capa más fina (Parte Inferior) hacia la más gruesa (Parte Superior)

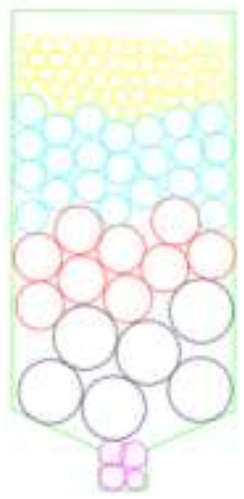

\section{E. Construcción del prototipo}

La construcción del prototipo se lo hará utilizando envases reciclables (debido al cuidado medio ambiental), por lo cual se ocupará una botella plástica de agua, el mismo que será el depósito de los diferentes materiales filtrantes y en diferentes proporciones, los mismos que han sido dispuestos desde la capa más fina de material, en este caso el algodón será el primer elemento filtrante, seguido de este se ubicará carbón activado , arena fina, grava fina, mediana y por ultimo grava gruesa con el fin de retener de mejor manera los sólidos suspendidos en el agua contaminada ver Fig. 3., la parte superior estará descubierta para depositar allí el agua. Por la parte inferior del filtro, se colocará otro recipiente del mismo diámetro al del filtro para que allí se deposite el agua filtrada. 
Para que la filtración sea lo suficientemente eficiente, el fluido será filtrado de 2 a 3 veces seguidas, para finalmente obtener el agua apta para el consumo de una persona vegana, por lo que será necesario un recipiente extra donde se deposite el agua sobrante, mientras el recipiente contenedor del agua principal está vertiendo el agua nuevamente en el filtro.

\section{F. Contaminación del agua.}

La contaminación del agua puede ser por medios físicos o químicos, es decir que el agua contaminada presenta partículas radioactivas, y posee sólidos en suspensión de algún compuesto en cuanto a la contaminación física, mientras que al otro tipo de contaminación el agua puede contener algún compuesto o elemento indeseable que puede ser nocivo a la salud, como por ejemplo: aceites, amoniacos, cloruros, por último el agua también presenta contaminación microbiológica, que tienen gran impacto en la salud de las personas.

Para la comunidad vegana el agua debe ser lo más pura y limpia posible, para ellos estos parámetros de contaminación deben ser mucho más estrictos, esto quiere decir que el agua no debe poseer ningún compuesto químico como el cloro u otros agentes, que como son conocidos, son utilizados para la desinfección y potabilización del agua, para ser apta para el consumo humano, pero para la comunidad vegana es inaceptable dichos compuestos.

\section{G. Parámetros de calidad del agua:}

Cuando se inserta un material del tipo físico, químico o biológico en elementos hídricos estos afectan a la calidad del agua, a continuación, se muestran varios factores que inciden en esta:

Fig. 4. Esquema de las causas de la reducción calidad del agua. [8]

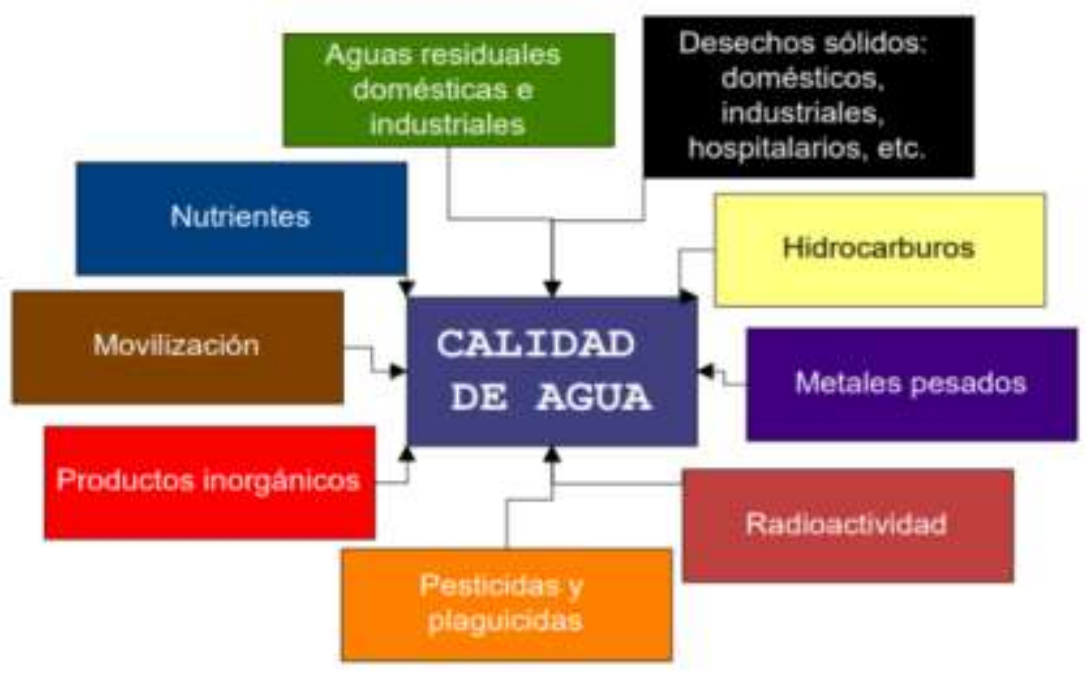


Entre los parámetros más importantes que inciden en la calidad del agua están:

$p H: \mathrm{El} \mathrm{pH}$ el potencial de hidrogeno hace referencia para saber si una sustancia es acida o alcalina, el agua pura posee un $\mathrm{pH}$ de 7 , esto significa que la sustancia es neutra. Un agua apta para el consumo debe ser neutra o estar con valores cercanos a esta.

Conductividad: es la concentración de sales que se encuentran solubles en el agua, para poder medir la conductividad se lo debe realizar mediante un conductimetro, también depende de la temperatura, si es alta la temperatura admite más conductividad [10]

Turbiedad: medida en la cual el agua pierde transparencia debido a solidos extraños dentro del mismo, mientras más partículas existen, más turbio es el líquido [11]

Color: Es causado por los materiales que se encuentran disueltos en el fluido, existe el color aparente que es el que se tiene de muestras con los sólidos suspendidos entre otros, y el color real que llega después de haber filtrado el mismo [12]

Sólidos suspendidos: Partículas que se encuentran en suspensión del agua por el movimiento del fluido debido a la baja densidad del sólido, los mismos pueden ser de carácter orgánico e inorgánico [13]

Sólidos disueltos: Es la adición de minerales, sales, metales, entre otros que se encuentran disueltos en el agua, lo cual se le puede tomar como a cualquier otro elemento que no sea $\mathrm{H} 2 \mathrm{O}[14]$

Cloruros: el ion cloruro no es un elemento perjudicial para la salud humana, pero si es un indicativo de la contaminación del agua ya que la concentración es mayor en aguas residuales, y la actividad humana incrementa dicho ion [15]

Alcalinidad: es la medida de los hidrógenos, los cuales son iones ácidos en el agua y es producido por los contenidos de carbonatos y bicarbonatos, la alcalinidad permite regular los niveles de $\mathrm{pH}$ dejando que no llegue a ser básico o acido en un grado alto [16]

Amonios: es un indicativo de contaminación dentro del agua, la principal causa es el agua estancada [17]

Fosfatos: se encuentran añadidos de forma artificial debido a productos detergentes debido a lavado de ropa o limpieza, fertilizantes, abonos, influyen de manera negativa en el agua. [18]

\section{H. Norma NTE INEN 1108 "AGUA POTABLE. Requisitos"}

Esta norma establece los requisitos que debe cumplir el agua potable para consumo humano, se aplica al agua potable de los sistemas de abastecimiento públicos y privados a través de redes de distribución y tanqueros [19]. El documento presenta varios parametros como: 
- Parámetros de calidad del agua y sus unidades de medida.

- Lista de contaminantes en el fluido y sus límites permisibles para el consumo humano.

- Criterios para la calidad de agua

- Métodos para la determinación de contaminantes en el agua

El agua se considera de consumo humano y uso doméstico cuando se emplea como:

- Preparación de alimentos y como bebida

- Fabricación de alimentos

- Se emplea como higiene personal y para limpieza de materiales o utensilios

Según el Laboratorio Calidad de Agua de la Facultad de Ciencias de la Escuela Superior Politécnica de Chimborazo dicta que los parámetros referenciales de la Tabla 1 permiten determinar si el agua es consumible o no según la norma NTE INEN 1108.

Tabla 1. Parámetros de componentes permisibles en el agua

\begin{tabular}{lcc}
\hline \multicolumn{1}{c}{ Parámetros } & Valor Referencial & Unidades \\
\hline $\mathrm{pH}$ & $6.5-8.5$ & \\
Conductividad & $<500$ & $\mu$ Siems/cm \\
Turbiedad & $<5$ & $\mathrm{UNT}$ \\
Color & $<15$ & $\mathrm{Pt} / \mathrm{Co}$ \\
Sólidos & $<2$ & $\mathrm{mg} / \mathrm{L}$ \\
Suspendidos & $<300$ & \\
Sólidos Disueltos & $<250$ & $\mathrm{mg} / \mathrm{L}$ \\
Cloruros & $<250$ & $\mathrm{mg} / \mathrm{L}$ \\
Alcalinidad & $<0.5$ & $\mathrm{mg} / \mathrm{L}$ \\
Amonios & $<0.3$ & $\mathrm{mg} / \mathrm{L}$ \\
Fosfatos & $\mathrm{mg} / \mathrm{L}$ \\
\hline
\end{tabular}




\section{Metodologia.}

Tabla 2. Descripción de capas de los materiales en el contenedor (Filtro)

\begin{tabular}{cc}
\hline MATERIALES & $\begin{array}{c}\text { ESPESOR DE } \\
\text { CAPA }(\mathbf{c m})\end{array}$ \\
\hline Carbón & 2 \\
Arena Fina & 4.5 \\
Arena Gruesa & 3 \\
Grava fina & 3 \\
Grava gruesa & 2 \\
Canto rodado & 7 \\
\hline
\end{tabular}

Botella plástica de agua de $600 \mathrm{ml}$.

Fig. 5. Recipiente Plástico

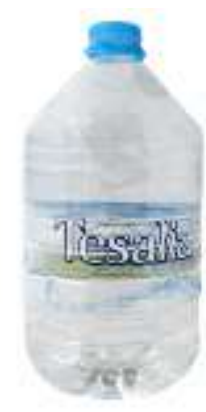

\section{Algodón}

Fig. 6. Algodón

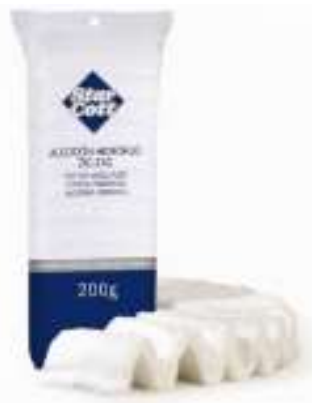


Arena, carbón y grava de distintos tipos

Fig. 7. Carbón

Fig. 8. Arena Fina
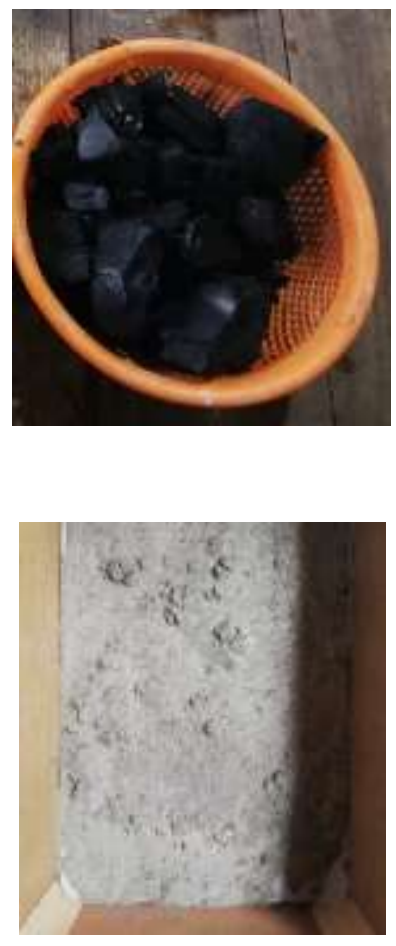

Fig. 9. Arena Gruesa

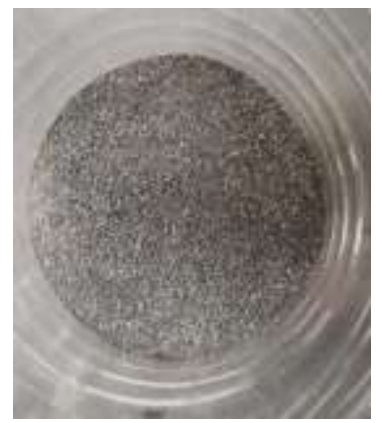

Fig.10. Grava Fina

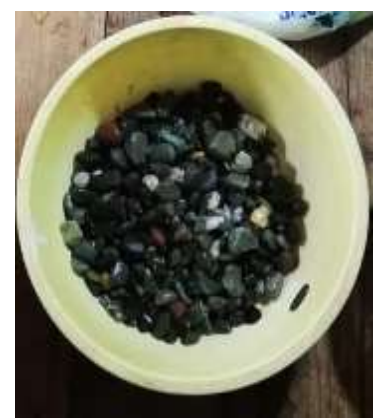


Fig. 11. Grava Gruesa

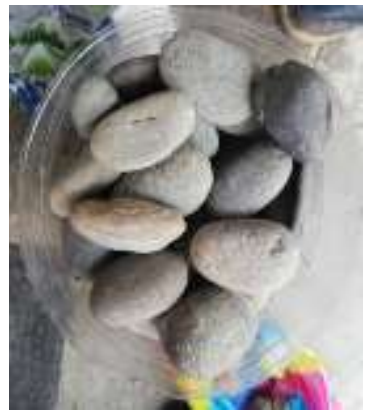

Fig. 12. Base Metálica.

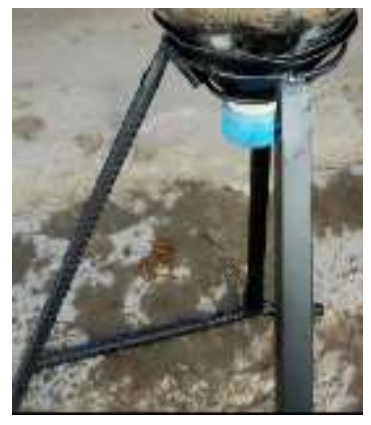

Procedimiento de construcción

1. Primero se escogió y limpió un envase plástico de $600 \mathrm{ml}$ donde se va a depositar los elementos filtrantes.

2. Se procedió a cortar la parte superior de la botella para que sirva como entrada del agua a ser filtrada.

3. Se realizó el lavado de todos los elementos filtrantes por separado.

4. Los elementos filtrantes se dejaron secar por un lapso de 2 días.

5. Transcurrido este tiempo se procedió a colocar una capa de $10 \mathrm{~cm}$ de algodón como primera etapa filtrante.

6. Después se procedió a colocar de manera uniforme una capa de $2 \mathrm{~cm}$ de carbón activado y triturado a la vez.

7. Luego se colocó una capa de arena fina de $4.5 \mathrm{~cm}$ de espesor

8. Posterior a esto se colocaron capas de grava fina y gruesa de 3 y $2 \mathrm{~cm}$ de espesor respectivamente.

9. Finalmente se colocó la capa más gruesa que en este caso es de canto rodado un espesor de $7 \mathrm{~cm}$.

Fig. 13. Filtro terminado

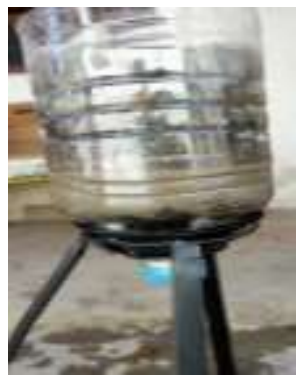


Procedimiento de filtración

1. Previo a la filtración del agua se lava el filtro tres veces seguidas para eliminar impurezas presentes en cada capa filtrante.

2. Se coloca un recipiente captador por la parte inferior del filtro

3. Se deposita una cantidad considerada de agua en la parte superior del filtro.

4. Se espera el tiempo necesario hasta que filtre todo el volumen de agua depositado

5. Por último se debe repetir el procedimiento 3 o 4 veces, para un filtrado más eficiente.

\section{Resultados.}

Mediante los exámenes: físicos, químicos y bacteriológicos realizados en las muestras de dos vertientes; se obtuvieron los siguientes resultados:

A. Vertiente A

Tabla 3. Resultados de examen físico químico Vertiente A.

\begin{tabular}{lcc}
\hline \multicolumn{1}{c}{ Parámetros } & $\begin{array}{c}\text { Muestra } \\
\text { Cruda }\end{array}$ & $\begin{array}{c}\text { Muestra } \\
\text { Filtrada }\end{array}$ \\
\hline $\mathrm{pH}$ & 8.01 & 7.83 \\
Conductividad ( $\mu$ Siems/cm) & 787 & 819 \\
Turbiedad (UNT) & 5.17 & 1.58 \\
Color $(\mathrm{Pt} / \mathrm{Co})$ & 83 & 64 \\
Sólidos Suspendidos (mg/L) & 43 & 6 \\
Sólidos Disueltos(mg/L) & 470 & 490 \\
Cloruros(mg/L) & 63.8 & 53.2 \\
Alcalinidad(mg/L) & 510 & 425 \\
Amonios (mg/L) & 0.265 & 0.365 \\
Fosfatos (mg/L) & 0.036 & 0.183 \\
\hline
\end{tabular}


Tabla 4. Resultados del examen microbiológico Vertiente B

\begin{tabular}{ccc}
\hline \multicolumn{1}{c}{ Parámetro } & $\begin{array}{c}\text { Muestra } \\
\text { Cruda }\end{array}$ & $\begin{array}{c}\text { Muestra } \\
\text { Filtrada }\end{array}$ \\
\hline Coliformes Totales (UFC/100ml) & 600 & Incontable \\
Coliformes Fecales (UFC/100ml) & Ausente & Ausente \\
\hline
\end{tabular}

Fig. 14. Muestra cruda (izquierda) y Muestra Filtrada (derecha) de la Vertiente A

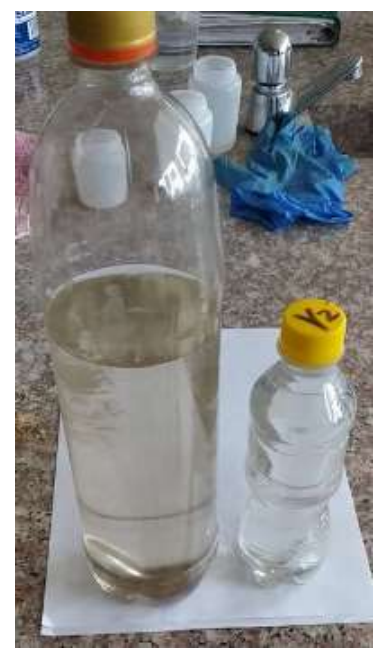

Fig. 15. Examen microbiológico Muestra cruda (A1) y Muestra Filtrada (A2) de la Vertiente A

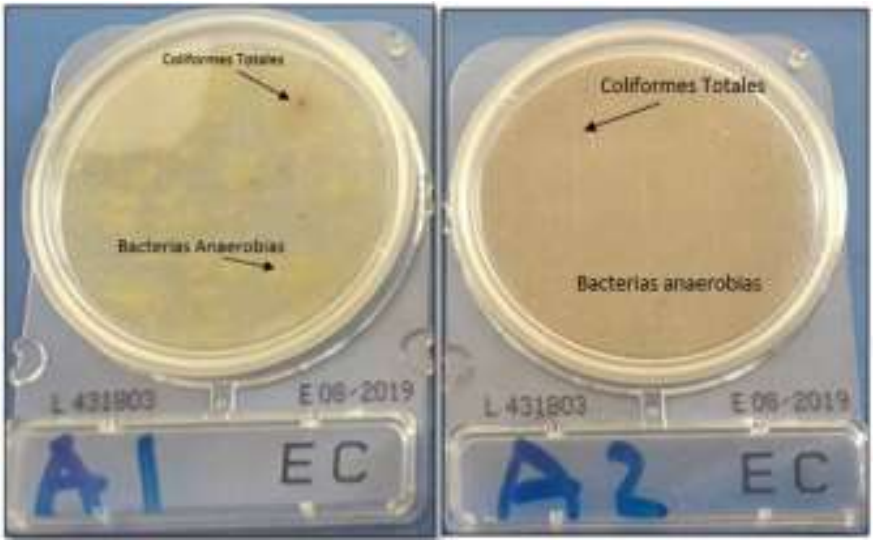

a. Vertiente B 
Tabla 5. Resultados de examen físico químico Vertiente B.

\begin{tabular}{ccc}
\hline Parámetros & Muestra Cruda & Muestra Filtrada \\
\hline $\mathrm{pH}$ & 7.77 & 7.62 \\
$\begin{array}{c}\text { Conductividad } \\
(\mu \text { Siems/cm) }\end{array}$ & 570 & 560 \\
$\begin{array}{c}\text { Turbiedad (UNT) } \\
\text { Color (Pt/Co) }\end{array}$ & 0.28 & 2.32 \\
$\quad$ Sólidos & 7 & 98 \\
$\begin{array}{c}\text { Suspendidos } \\
(\mathrm{mg} / \mathrm{L})\end{array}$ & 2 & 11 \\
$\quad$ Sólidos & 300 & 237 \\
$\begin{array}{c}\text { Disueltos }(\mathrm{mg} / \mathrm{L}) \\
\text { Cloruros }(\mathrm{mg} / \mathrm{L})\end{array}$ & 33.3 & 36.9 \\
Alcalinidad(mg/L) & 340 & 355 \\
Amonios (mg/L) & 0.01 & 0.65 \\
Fosfatos (mg/L) & 0.056 & 0.128 \\
\hline
\end{tabular}

Tabla 6. Resultados del examen microbiológico Vertiente B

\begin{tabular}{ccc}
\hline Parámetro & Muestra Cruda & Muestra Filtrada \\
\hline Coliformes & & \\
Totales & 700 & Incontable \\
(UFC/100ml) & & \\
Coliformes & & \\
Fecales & Ausente & Ausente \\
$(\mathrm{UFC} / 100 \mathrm{ml})$ & & \\
\hline
\end{tabular}


Fig. 16. Muestra cruda (izquierda) y Muestra Filtrada (derecha) de la Vertiente B.

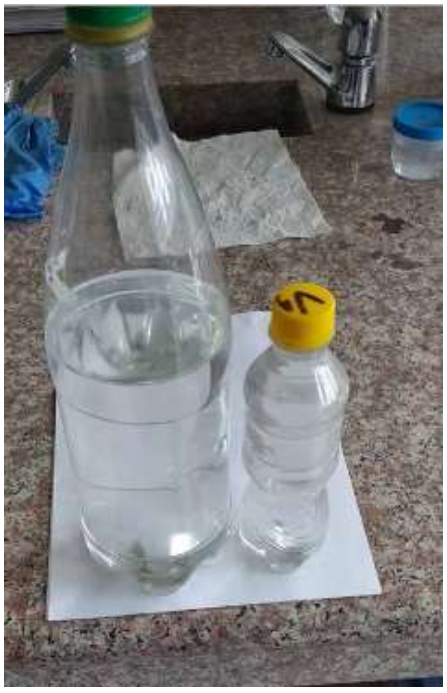

Fig. 17. Examen microbiológico Muestra cruda (B1) y Muestra Filtrada (B2) de la Vertiente B.

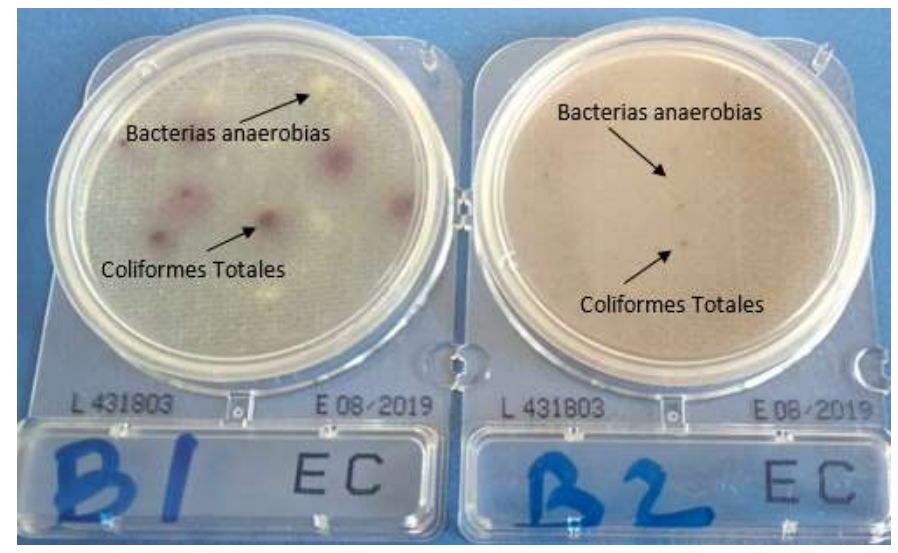

\section{Análisis de Resultados}

Para la toma de muestras se realizó por tres ocasiones consecutivas un lavado previo del filtro, con el fin de eliminar las impurezas presentes en las capas filtrantes, así como también el proceso de filtrado de cada muestra se lo repitió tres veces.

Con la experimentación realizada se pudo observar que el proceso de filtrado no tuvo los mismos resultados para ambas vertientes de análisis. En el caso de la vertiente A el filtro mostro una efectividad ya que se evidencio que ciertos parámetros de calidad del agua tales como: turbidez, color, pH, entre otros (Ver Tabla 3) se encontraban dentro de los rangos establecidos, por lo que el agua filtrada de esta vertiente podría ser consumida según el criterio de los exámenes físicos y químicos; mientras que para el análisis microbiológico la 
cantidad de Coliformes Totales (Ver Tabla 4) encontrados en las muestras están fuera del rango admisible para el consumo humano.

Para la vertiente B el filtro no cumplió con su propósito ya, que, en lugar de limpiar el agua, el filtro aumento las concentraciones de los análisis físicos y químicos evaluados (Ver Tabla 5) en la muestra filtrada con respecto de la muestra cruda, esto pudo haber sido causado por la degradación de las partículas y las impurezas presentes en el filtro ${ }_{2}$ es por esto que según los criterios de aceptación de los exámenes físicos y químicos los parámetros de calidad de agua evaluados no son aceptables para el consumo humano; mientras que los resultados del examen microbiológico muestra que la cantidad de Coliformes Totales (Ver Tabla 6) es mucho mayor que la muestra cruda.

En cuanto al análisis microbiológico se pudo evidenciar que ambas muestras presentan gran cantidad de Coliformes Totales y bacterias anaerobias lo cual impide que el líquido sea apto para el consumo, además se recalca también que las muestras no presentan Coliformes fecales que en parte sería un factor mucho más perjudicial en el agua.

\section{Conclusiones.}

- El filtro tuvo efectividad para el tratamiento de la vertiente A ya que se redujeron algunos parámetros de calidad e hicieron de esta un agua más apta para el consumo humano. En el caso de la vertiente B cuyo líquido es prácticamente limpia antes del filtrado en esta ocasión ensucio la muestra convirtiéndola a esta en agua no apta para el consumo humano.

- Mediante los resultados obtenidos en el análisis de las vertientes se determinó que el filtro se encontraba disolviendo partículas en lugar de retenerlas, esto se evidencio con el incremento de la conductividad de la muestra filtrada, por /ende, se presume que una de las capas filtrantes (arena marina) debido a su composición podría estar contaminando el agua en lugar de limpiarla.

- Con los resultados obtenidos se presume que previo al proceso de filtración debió estar contaminado debido a las pruebas microbiológicas se observaron colonias de Coliformes Totales en las muestras sin filtrar mientras que el agua filtrada aparte de encontrar otras bacterias los Coliformes Totales progresaron de manera más eficaz.

- En vista de los resultados obtenidos se puede identificar que para alcanzar una filtración optima se debe tomar en cuenta muchos parámetros como la limpieza profunda tanto del filtro como de sus componentes, de ser posible hay que lavarlas y refrigerarlas por un momento para esterilizarlas con esto se lograría una mejora parcial de los parámetros de calidad del agua filtrada.

- Como la presente investigación está orientada a la comunidad vegana los expertos en temas de calidad de agua indican que para lograr que el agua sea apta para el consumo humano obligadamente debe tener un proceso de cloración y que por más limpia que parezca una vertiente el utilizar un filtro casero no garantizara la calidad de agua para su consumo. 


\section{Referencias bibliográficas.}

[1] Jumapam.gob.mx. (2018). Distribución de Agua en el Planeta | Jumapam. [online] Available at: http://jumapam.gob.mx/cultura-del-agua/distribucion-de-agua-en-elplaneta/ [Accessed 6 Nov. 2018].

[2] Fundación Aquae. (2018). Principales datos del agua en el mundo | Fundación Aqua[onlinee. [online] Available at: https://www.fundacionaquae.org/wiki-aquae/datosdel-agua/principales-datos-del-agua-en-el-mundo/ [Accessed 6 Nov. 2018].

[3] Pudeleco.com. (2018). AGUA POTABLE. REQUISITOS. [online] Available at: http://www.pudeleco.com/files/a16057d.pdf [Accessed 6 Nov. 2018].

[4] Aguapotable.unach.edu.ec. (2018). ...:Estadisticas de calidad del agua para consumo humano - Calidad del agua de Riobamba::... [online] Available at: http://aguapotable.unach.edu.ec/estadisticas/calidadAgua/calidadRiobamba/109 [Accessed 6 Nov. 201 (HUMMA, 2017)8].

[5] Huma. Cómo funciona el carbón activado. [online]. Available at: https:/humma.com.ar/como-funciona-el-carbon-activado/

[6] JBL. Material filtrante adecuado. [online]. Available at: https://www.jbl.de/es/areas/section/41/el-material-filtrante-adecuado.

[7] Tejero,J. Filtración [ [ online]. Available at: ftp://ceres.udc.es/Grado_TECIC/Cuarto_Curso/Ingenieria\%20Ambiental/Filtracion/TE MA-filtraci\%C3\%B3n rev140211-ajb.pdf

[8] Chang, J. (2016). Calidad del agua. [online] Dspace.espol.edu.ec. Available at: https://www.dspace.espol.edu.ec/bitstream/123456789/6145/2/Calidad\%20de\%20Agua \%20Unidad\%201,2,3.pdf [Accessed 13 Jan. 2019].

[9] Sanchez, D. (2019). Calidad del Agua y su Control. [online] Blog.uclm.es. Available at: http://blog.uclm.es/davidsanchezramos/files/2016/05/11_Calidad-agua-ycontrol_v2015_resumen.pdf [Accessed 13 Jan. 2019].

[10] Sanchez, D. (2019). Calidad del Agua y su Control. [online] Blog.uclm.es. Available at: http://blog.uclm.es/davidsanchezramos/files/2016/05/11_Calidad-agua-ycontrol_v2015_resumen.pdf [Accessed 13 Jan. 2019].

[11] Fcca.es. (2019). Conductividad eléctrica del agua. [online] Available at: http://fcca.es/documentos/05_documentos_por_temas/Estandares\%20de\%20calidad\%2 0de\%20las\%20aguas\%20Tablas\%20de\%20estandares(3)/Salinidad_del_agua_de_riego .pdf [Accessed 1 Feb. 2019].

[12] Lenntech.es. (2019). Turbidez. [online] Available at: https://www.lenntech.es/turbidez.htm [Accessed 1 Feb. 2019].

[13] Quimicotecnica.com. (2019). Medición del Color | Quimico Tecnica Industrial. [online] Available at: http://quimicotecnica.com/tip-color-measurement/ [Accessed 1 Feb. 2019]. 
Vol. 3, N³, p. 337-355, julio - septiembre, 2019

[14] S.A.S., G. (2019). Sólidos en suspensión. [online] Co.grundfos.com. Available at: https://co.grundfos.com/service-support/encyclopedia-search/suspended-solids.html [Accessed 1 Feb. 2019].

[15] (TDS), S. (2019). ¿Qué son los sólidos disueltos totales? TDS - Carbotecnia. [online] Carbotecnia. Available at: https://www.carbotecnia.info/encyclopedia/solidos-disueltostotales-tds/ [Accessed 1 Feb. 2019].

[16] Escritoscientificos.es. (2019). Cloruros en aguas. [online] Available at: http://www.escritoscientificos.es/trab21a40/clorurosaguas/00cloruros.htm [Accessed 1 Feb. 2019].

[17] Xtec.cat. (2019). Presencia de fosfato en aguas. [online] Available at: http://www.xtec.cat/ gjimene2/llicencia/students/05aguas.html [Accessed 1 Feb. 2019].

[18] Xtec.cat. (2019). Presencia en aguas del amonio. [online] Available at: http://www.xtec.cat/ gjimene2/llicencia/students/07aguas.html [Accessed 1 Feb. 2019].

Norma NTE INEN 1108 “AGUA POTABLE. Requisitos”. [online] Available at: https://www.dspace.espol.edu.ec/bitstream/123456789/10608/8/Norma\%20Inen\%20Ag ua1108-2.pdf [Accessed 1 Feb. 2019]. 


\section{PARA CITAR EL ARTÍCULO INDEXADO.}

Mayorga Pérez, D., Tapia Segarra, I., Paredes, L., \& Caicedo Reyes, J. (2019). Diseño y Construcción de un filtro de agua vegana. Ciencia Digital, 3(3), 337-355. https://doi.org/10.33262/cienciadigital.v3i3.649

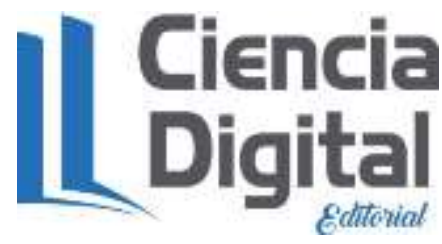

El artículo que se publica es de exclusiva responsabilidad de los autores y no necesariamente reflejan el pensamiento de la Revista Ciencia Digital.

El artículo queda en propiedad de la revista y, por tanto, su publicación parcial y/o total en otro medio tiene que ser autorizado por el director de la Revista Ciencia Digital.
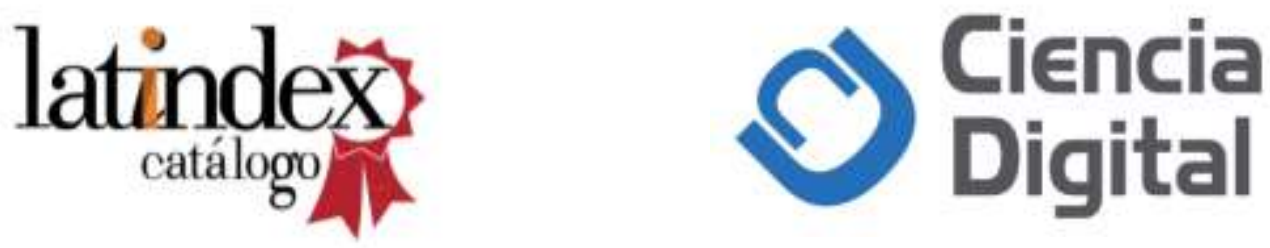